\title{
The Role of Institutional Work in Platform Establishment: An Investigation of Digital Innovation Practices for Creating, Maintaining and Disrupting Institutions
}

\author{
Taline Jadaan \\ Swedish Center for Digital Innovation, Department of Informatics, Umeå University, Sweden \\ taline.jadaan@umu.se
}

\begin{abstract}
While the significance of digital platforms for contemporary organizations has been demonstrated both in theory and practice, how they emerge is less understood. We argue that one source of digital platform emergence is the recombinatorial innovation processes individuals enact in organizational work practices. We draw on the theory of institutional work to empirically examine how innovation processes led to the emergence of a digital platform in the Swedish transport administration. We find that actors engage in work aimed at creating, maintaining and disrupting socio-technical structures. These work practices involve exploring the possibilities of specific digital resources, their combinatorial options, and how new resources can be generated. The analysis contributes to the literature on digital platforms by (1) demonstrating the role of digital malleability in bypassing institutional resistance, (2) identifying temporal patterns and dependencies of activities, and (3) detecting distinct emphasis in types of institutional work.
\end{abstract}

\section{Introduction}

The coordination and carrying out of activities in contemporary organizations is increasingly facilitated by digital platforms, making the processes through which they emerge as an important area of investigation. For example, in a recent literature review de Reuver et al. point to the lack of knowledge on such processes and asked if $[1, p .130]$ "products and services (or perhaps applications) evolve into platforms as 'accidental results' or can they be consciously designed?". The recombinatorial possibilities of digital resources suggest that the answer is 'both' as they exhibit a "procrastinated binding of form and function" [2, p. 1399]. The reprogrammability, homogenization of data, and the self-referential nature of digital resources [3], combined with standards for interoperability [4], provides unprecedented possibilities for recombination in design [5]. These characteristics also enable recombination in use as individuals or collectives enact distinct combinations of available resources when carrying out their tasks [5]. Overall, these features suggest opportunities for platform emergence through use patterns where certain resources become central for other actors and forms a "core" for other technologies, and through purposeful recombination in design as the trigger for platform emergence (which later often is "tuned" as interaction patterns deviate from the expected, c.f. [6]).

Digital innovation has been argued to challenge the organizing logics of traditional innovation processes. The outcomes are subject to continuously shifting boundaries (structurally, spatially, and temporally), agency is distributed among an evolving set of actors, and boundaries between innovation processes and outcomes are blurred as they shape and are being shaped by each other [7]. To investigate the specific case of digital innovations that lead to the establishment of digital platforms, we draw on institutional work. The study of digital innovation through an institutional work lens mainly focuses on how digitally enabled institutional arrangements to emerge and diffuse [8]. As such, the combination of theory on combinatorial digital innovation and institutional work provides tools to analyze both problem-solution paring involved with the recombination of digital resources and the social mechanism in play. To this end, this study explores the following research question: how is institutional work involved in the combinatorial innovation processes underlying digital platform emergence?

We report on a longitudinal study of the emergence of a digital platform in the Swedish Transport Administration (STA). We analyze how the search for useful resource pairing lead to multiple cycles of institutional processes for creating, maintaining and disrupting institutional arrangements. The analysis provides an empirical demonstration of the role of technological 
malleability in bypassing institutional resistance in digital innovation in general and platform emergence in particular. Further, we identify a temporal pattern in the innovation process in which digital resources in the device and network layer enable later growth of resource in the service and content layers. Finally, we demonstrate distinct emphasis in institutional work types.

\section{Theoretical background}

\subsection{Digital innovation and platforms}

Technical platforms in general are here understood as "evolving organizations or metaorganizations that: (1) federate and coordinate constitutive agents who can innovate and compete; (2) create value by generating and harnessing economies of scope in supply or/and in demand; and (3) entail a modular technological architecture composed of a core and a periphery" [9, p. 1240]. As specific instances of technological platforms, digital platforms also have an "extensible codebase of a software-based system that provides core functionality shared by the modules that interoperate with it and the interfaces through which they interoperate" [10, p. 676]. The architectural separation into a core and periphery enables re-use and standardization of shared resources while distributing selected decision right for design. The distribution of decision rights enables actors in the external environment to draw on available assets when developing customized solutions based on a specific understanding of the context of use. These features have led scholars to suggest that individual platform configurations enable distinct architectural leverage concerning production, innovation, and transactions [11].

Regarding architecture, the core of digital platforms might be located in one or more of the networks, device, service and content layers of digital architecture [3, 5, 12]. While for example, Apple (with varying success) has explored configurations encompassing multiple layers, other remains focused on a specific one (e.g., Spotify focuses on the service layer and so far, avoids proprietary devices). Here we mainly focus on digital service platforms since digital product platforms might be subject to distinct logics and dynamics in their digital innovation processes (e.g. $[13,14])$. Studies on the creation and diffusion of technological platforms have suggested high-level insights such as fulfilling a relevant function for an industry, ensuring dependence between components, protecting its core source of revenue [15], and "igniting" network-effects by achieving a critical mass [16]. Moreover, extant literature provides rich insights into issues related to digital platforms' governance, architecture and their internal fit (c.f. [6, 17-19]. However, the actual innovation processes through which digital platforms emerge has received little attention. To conceptualize such processes, we draw on the distinction between recombination of digital resources through design and use [5].

Digital resources, i.e. "entities that serve as building blocks in the creation and capture of value from information" [5, p. 90], are not only relatively easily combined in design processes of technology, but also in the context of use. The act of design recombination here refers to "the activity of generating a value path by connecting digital resources as a value offer to users" while use recombination refers to "the activity of generating an individual value path by connecting digital resources in use" [5, p. 92]. A value path broadly means the way different digital resources are connected and collectively enacted. As designers engage in digital innovation processes, they go through stages of discovery and development before they try to spread the outcome. In the discovery stage, they engage in search for fruitful combinations to invent, they select among available options, and they test [20]. In the development stage, they use the result of the discovery stage to package or configure digital resources into an attractive offering that channels users towards certain value paths. If successful, the innovation is diffused among actors in a target population that might, or might not, choose to adopt it, and different degrees of the suggested value path. Often, even successful channeling towards certain value paths will only include partial adoption of the value path designers intended as users will apply the available digital resources in ways they deem useful in their specific context and activities. To understand the context in which such digital innovation happens for incumbent firms, we draw on the lens of institutional work.

\subsection{Institutional work}

The notion of institutional work, "the purposive action of individuals and organizations aimed at creating, maintaining and disrupting institutions" [21, p. 216], emphasizes how agency is embedded in institutional contexts forming actions, intentions, and rationality [22]. An institutionalist perspective assumes that institutions constitute durable elements "that have a profound effect on the thoughts, feelings, and behavior of individual and collective actors" [21, p. 216]. For any analysis of institutional change, the understanding of what constitutes an institution is fundamental. Here we adopt Scott's [23, 
p. 48] description of institutions as consisting of "cultured-cognitive, normative and regulative elements that ... provide stability and meaning to social life ... Institutions are transmitted by various types of carriers, including symbolic systems, relational systems, routines, and artifacts' and they 'operate at multiple levels of jurisdiction".

As digitalization encompasses and changes organizational practices, digital technology is an increasingly important materialization of institutions [22]. Digital technologies constitute both material objects that through their design and functionality limits and shapes the institutional logic and represent instantiations of symbolic and cognitive aspects affecting their design $[22,24]$. Thus, they are both carriers and effects of institutional logics. Applying an institutional perspective on digital innovation, Hinings et al. [8] emphasize the standards that digital institutional infrastructures (e.g., platforms) impose thereby "enabling, constraining and coordinating numerous actors' actions and interactions in ecosystems, fields or industries." As such, analyses of digital innovation processes in general, and those involving the imposition of platforms logics, in particular, requires detailed consideration of both digital technologies and the symbolic and cognitive context in which innovation processes occur.

Labeled according to aims, Lawrence and Suddaby [21] identifies three broad categories of institutional work - creating, maintaining, and disrupting institutions - and suggest that these correspond to the 'rough life-cycle' of institutions. Drawing on this categorization of institutional work, we understand digital innovation processes as triggering, involving, and unfolding in, antagonistic types of institutional work for different purposes. When actors with distinct understandings, motives, and positions engage in or become subject to, innovation processes they will respond differently. These responses can involve actions to create new institutional elements, maintain the status quo, or disrupt the current order.

Since both organizational and technological systems are nested hierarchies, i.e., systems containing other systems, the life-cycles of the many interacting subsystems are prone to clash. As actors committed to one or multiple subsystems engage in institutional work to maintain them, other institutional work practices are enacted to create new arrangements from the perspective of another subsystem. Similarly, from the viewpoint of a third subsystem, other actors might engage in work practices to disrupt. Thus, multiple types of institutional work with antagonistic aims are likely to coincide in digital innovation processes. This conceptualization is graphically illustrated in figure 1.

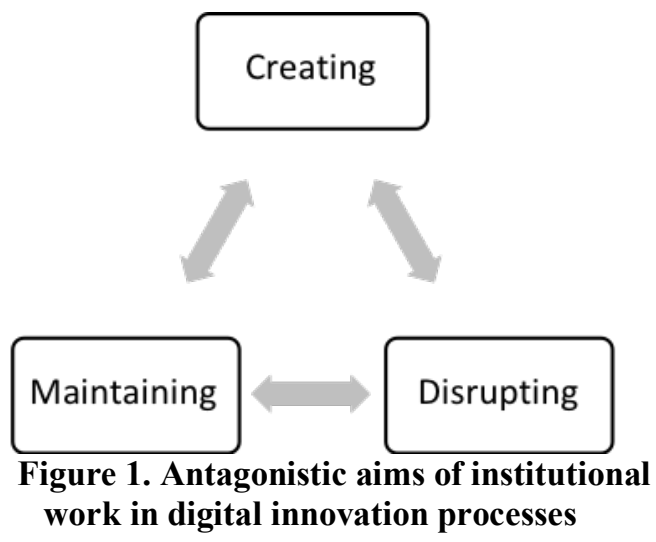

Based on their extensive literature review, Lawrence and Suddaby (2006) also identifies specific types and forms of work practices aligned with the aims of these categories. Creating institutions involve overtly political work, reconfiguration of belief systems and alterations of categorizations to change 'meaning systems.' Maintaining institutions involve ensuring obedience to rule systems and reproducing the existing norms and beliefs. Disrupting institutions include destabilizing the mechanisms that uphold institutional arrangements by making members complying with them. Table 1 details types of institutional work for each category, and specific forms of work practices.

\begin{tabular}{|c|c|c|}
\hline Category & Type & $\begin{array}{l}\text { Forms of work } \\
\text { practices }\end{array}$ \\
\hline \multirow[t]{3}{*}{$\begin{array}{l}\text { Creating } \\
\text { institutions }\end{array}$} & $\begin{array}{l}\text { Overtly political } \\
\text { work }\end{array}$ & $\begin{array}{l}\text { - Advocacy } \\
\text { - Defining } \\
\text { - Vesting }\end{array}$ \\
\hline & $\begin{array}{l}\text { Reconfiguration } \\
\text { of belief system }\end{array}$ & $\begin{array}{l}\text { - Constructing } \\
\text { identities } \\
\text { - Changing norms } \\
\text { - Constructing } \\
\text { networks }\end{array}$ \\
\hline & $\begin{array}{l}\text { Alter abstract } \\
\text { categorizations to } \\
\text { change the } \\
\text { boundaries of the } \\
\text { meaning system }\end{array}$ & $\begin{array}{l}\text { - Mimicry } \\
\text { - Theorizing } \\
\text { - Educating }\end{array}$ \\
\hline \multirow[t]{2}{*}{$\begin{array}{l}\text { Maintaining } \\
\text { institutions }\end{array}$} & $\begin{array}{l}\text { Ensuring } \\
\text { adherence to rule } \\
\text { systems }\end{array}$ & $\begin{array}{l}\text { - Enabling } \\
\text { - Policing } \\
\text { - Deterring }\end{array}$ \\
\hline & $\begin{array}{l}\text { Reproducing } \\
\text { existing norms } \\
\text { and belief } \\
\text { systems }\end{array}$ & $\begin{array}{l}\text { - Valorizing/ } \\
\text { demonizing } \\
\text { - mythologizing } \\
\text { - Embedding and } \\
\text { routinizing }\end{array}$ \\
\hline \multirow[t]{2}{*}{$\begin{array}{l}\text { Disrupting } \\
\text { Institutions }\end{array}$} & \multirow{2}{*}{$\begin{array}{l}\text { Attacking or } \\
\text { undermining the } \\
\text { mechanisms that }\end{array}$} & $\begin{array}{l}\text { - Disconnecting } \\
\text { sanctions. }\end{array}$ \\
\hline & & - Disconnecting \\
\hline
\end{tabular}




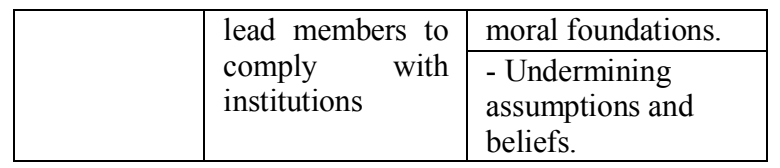

Table 1 Institutional work in organizations (adopted from Lawrence and Suddaby 2006)

Taken together, these concepts from the digital innovation literature and theory on institutional work provides us with a "sensitizing device" [25] through which to make sense of the digital platform emergence at STA.

\section{Methodology}

We conducted a longitudinal interpretative case study [26, 27], carried out between 2008 and 2017 at STA This research project began as a study of digital transformation and digital strategizing. At the outset, we sought to study how governmental institutions such as STA navigate the demands of digital services amongst their customers. However, as the technological and organizational focus changed, resulting in a digital platform, so did our research focus. We ended up following these actors as involved researchers [26] from the first initiatives to the development of a digital platform.

\subsection{Research context}

STA aims to create conditions for an economically efficient, internationally competitive, and long-term sustainable transport system. The organization has approximately 6800 employees, located at the headquarter in central Sweden and six regional offices. The administration was founded in 2010, as a result of merging former railroad and road administrations. According to the ministry of enterprise and innovation, the aim of establishing STA was to create an intermodal interpretation that would streamline scattered processes and enable involvement to all actors operating in the transport sector. We initiated our study at the Swedish railroad administration (SRA) and continued following the organization after the merger with the Swedish road administration in 2010. For readability, we herein referee to the organization both before and after the merger as STA.

\subsection{Data Collection and Data analysis}

We followed the work at STA between 2008 and 2017 with intense periods of on-site visits, interviews (45 in total) and interactions. The data collection was conducted in four phases between 2008 and 2017. During these phases, we turned to three different sources of data [27], semi-structured interviews, participant observation, and archival data. The first phase of the data collection, carried out as "chain referral" sampling [28] between February and June 2008, generated 13 interviews, informal interviews, internal documentation, and 15 onsite observations at SRA. The aim was to identify respondents that could provide an overview of the organization and IT related projects. Hence, this process allowed us to enrich our understanding of the organization and target significant respondents for future data collection phases. The conclusions drawn from the first phase turned our focus towards the digital platform initiative in the organization.

The second phase (September 08 - December 09) burrowed deeper into ongoing practices related to digital platform development. During this phase, we made onsite observations in the organization and interviewed 10 respondents involved in the process. Our understanding of the organization had by this phase reviled a need to understand the broader context STA operated within, including its customers.

During the third phase (Mars 10 - September 2011), 12 semi-structured interviews were carried out with STA's customers concerning potential benefits and obstacles with a service platform. Besides that, we carried out two workshops with representatives from STA. These workshops aimed to deliver feedback, verify our findings, and identify potential missing elements [27]. Phase four (September 2012 June 2017) focused foremost on understanding the process of establishing the platform.

Throughout the fourth phase, we conducted 13 interviews, several informal interviews, attended 20 project meetings and carried our five workshops. All 48 interviews were recorded and later transcribed, generating 45 hours of recorded material average 43 minutes with 25 respondents. Our participant observations occurred during 35 occasions, generating 257 hours of observations during project meetings, steering committee meetings, workshops, onsite observations at STA. Also, our study included a significant volume of archival data, including technical specifications and presentations.

\subsection{Data Analysis}

Data collection and analysis was partly carried out in parallel, as advocated by Miles and Huberman [29]. We initiated our data analysis by using an open coding procedure to discover relevant concepts in the data and group them into categories [30], trailing practices carried by the organization and how it affected the emergence of the digital platform. The first round of analysis helped us to identify current 
IT-related initiatives at STA and to develop an initial understanding of the organization. During the second round of the analysis, we detailed our understanding of how institutional work at STA generated values from the combinatorial options of digital resources with a particular focus on the emergence of the digital platform. The open coding procedure carried out during the two rounds of analysis generated several hundred descriptive concepts initially. To decrease similarity, we reviewed and compared all concepts to formulate preliminary definitions of more than 165 mutually exclusive concepts. Second, consistent with the principle of abstraction and generalization [25], we spent considerable effort iterating between theoretical abstractions related to platform literature, and institutional work literature and the descriptive concepts generated in the first step. Based on a temporal analysis of the categorization of events, we identified the phases and activities described in section 4. This iteration between abstracted conceptions and empirical observations resulted in an emergent understanding of institutional practices carried out in the organization the emergence of the digital platform. In addition to the interviews, annual reports allowed us to understand the direction the organization was heading in regards to delivering digital services to the customers. Project meetings did not only enable us to follow the development of the digital platform, but also to observe body language and facial expressions. The workshops carried out at STA, during our data collection and analysis, was an opportunity to not only deliver feedback to the organization but also verify our finding and identify potential missing elements [27].

\section{Results}

In 2017 STA launched a web service providing data feeds on the state of customers' railroad wagons. By combining data from detectors and other sources, operators would be able to track and trace the position and condition of their wagons, thus enhancing their operational processes. The launch of this service was enabled by a new platform aggregating data from both external resources, existing proprietary ones, and a multitude of newly generated ones. Underlying the emergence of this platform was substantial efforts to explore technological features, use requirements, and acceptable standardization for a vast range of actors, both in the Swedish and European railroad context. From a customer perspective, the web service was a longed-for outcome. From an organizational perspective, the digital platform represented an instantiation of ten years of work practices in a multitude of digital innovation processes involving internal and external individuals with various competencies and positions. Our analysis revealed three phases with distinct focus in this process, "exploring and customizing available resources," "negotiation of standards," and "platform realization."

\subsection{Exploring and customizing available resources: 2007-2011}

By the end of 2007, a technician by chance overheard the division manager of the marketing unit talking about how one user organization (a steel producing company) had started experimenting with RFID technology by tagging their wagons. However, STA's digital infrastructure did not provide any support for the use of such resources, and the manager had firmly communicated to the steel company that it wouldn't do so in the near future either since he did not consider it to fall within the domain of the organization's operations.

Thus, the infrastructure and the unwillingness to develop it hindered design combination of digital resources to occur. The technician realized that RFID technology had significant potential for improving synchronization and efficiency of intra-organizational processes. However, he neither had the technical know-how or the political mandate to initiate formal innovation processes related to RFID. Instead, to increase the organizational understanding of the potential benefits of the technology (e.g., cost reduction for transportation, time-based maintenance, and automation of manual tasks) he contacted a RFID consultant, RFID suppliers, and customers. In 2008 he also started experimenting with the technology in his spare time (e.g., hiring a landing strip and using his car to investigate the speed limits which different RFID tags and readers worked).

"You need to be a shrewd person when you work with something you believe in, so no one else comes in and denigrate your work or devilry the process. ...The management said that it (investigating RFID) was not our (my) job, and that is pretty normal that management has that view in large organizations, but I don't agree with that. You should stick to your beliefs, if you have creative ideas, and try to elaborate on them." (Technician at STA).

In their existing infrastructure, STA had a significant number of detectors for sensing deviations in the wheels and brakes in order to decrease damages on the rail when breakdowns occur. Being responsible for these detectors, the technician realized that he would be able to use the established communication resources for detector data if they were updated. To this end, an update was developed 
in-house and implemented (from DPC2 to DPC3). The system developer explains:

"I was asked by the technician if there were any possibilities that we could update the DPC system by adding some functionalities regarding gathering RFID data. He argued that the RFID-readers is a complement to the detectors and was installed in conjunction with the detector system along the track"

Once the infrastructural resources for experimenting with the technology was in place, the technician informed his manager that he had found a way to improve the use of current detector data by implementing RFID. The manager permitted him to set up the first pilot project to evaluate potential benefits related to positioning of both the train and the specific order of wagons. STA received information on the number of wagons and their order from the train operators through a system called OPERA. However, this information was manually reported and often inaccurate. In addition to demonstrating significant potential to remedy these problems, an important discovery in the project was that STA needed ways of distributing the generated data (at this time position of the train) to customers.

To provide such functionality, it was decided by the technician and the system developer to exploit existing digital recourses by adding functionality to a system, OUT/IN. OUT/IN was a system for exchanging traffic data (e.g., timetables) with customers. The idea was that OUT/IN would provide the first digital resource needed to communicate the RFID data to customers. More so, by exploiting existing resources, the technician argued that he would have a better chance to convince management of the benefits of the technology.

In 2009, the technician, together with the RFID consultant decided to assess tags from different providers, resulting in a technical evaluation of four different solutions. This evaluation included multiple pilot projects where tags were put on customers wagons (final results achieved in 2015 when a passive/active RFID tag was selected as the standard). The RFID consultant explains:

"We had a plan in mind when deciding to take several RFID providers on board, we thought that this was a great way to explore the technology and not "lock us" with one specific provider or a specific technical ability."

An important finding from the technical exploration and contacts with the RFID expert and the Finnish Railroad Administration (FRA) was that the European RFID standard (ISO18000-6 type A for wireless communication (between tag and reader) at the time) didn't allow reading in high speed (max 30 $\mathrm{km} / \mathrm{h}$ ). Since $60 \%$ of all railroad wagons in Sweden originates from a different European country, adoption at the EU level of a new standard (ISO18000-6 type C) with higher functional capacity (up to $160 \mathrm{~km} / \mathrm{h}$ ), was considered essential. This standard would enable infrastructure managers, railway companies and wagon owners to implement conjoint RFID systems, and hence reduce the amounts of RFID tags on each wagon. To this end, the internal STA supporters of the initiative engaged in collaborations with FRA to get acceptance of the new standard, which also happened in 2009.

Due to a large-scale EU project (Freightwise) RFID technology became interesting for the marketing manager within STA. As he sought to understand the technology and potential for STA, he realized that the technician and the people around him were the ones that knew both the technology and its potential applications. Thus, they became involved with other domestic and international actors seeking to improve information sharing. The marketing division manager explains:

"I didn't understand the RFID-technology, so I called the division manager at the maintenance division and asked about it, but he wasn't sure what the benefits would be for us to engage in such a project, so I had to contact the IT-strategist (at the maintenance division) and ask him for help. He told me that this technician had a hobby project during his spare time and that it was about RFID."

STA also commenced a collaboration with GS1 (a global standardization organ) under the name 'RFID in rail' and invited relevant actors to explore the potential of leveraging a new standard, EPCIS (aimed at identification of mainly physical) objects across processes). To this end, STA launched multiple pilot projects, identifying significant potential for value creation and together with GS1 worked to get acceptance of the standard at the EU level (including a workshop gathering all the major European railroad operators in Stockholm in 2010). By the end of 2011, 7 pilot projects exploring and demonstrating the potential usefulness of RFID technology and other data sharing technologies. During this phase, the technician engaged in certain disruptive practices such as demonstrating potential value for customers and promising future delivery of RFID based services that were not sanctioned by STA decision makers.

\begin{tabular}{|c|c|c|c|}
\hline Device & Network & Service & Content \\
\hline Detector, & RFID and & Customized & Data from \\
10 RFID & detector data & prototypes & detectors, \\
reading & communicated & for each & RFID, \\
stations, & through existing & customer & and \\
from 0- & network DPC3 & through & OPERA \\
150 RFID & connected to & OUT/IN & \\
tagged & UTIN where & & \\
\hline
\end{tabular}




\begin{tabular}{|c|c|l|l|}
\hline wagons & $\begin{array}{c}\text { customized } \\
\text { access for each } \\
\text { user organization } \\
\text { where designed }\end{array}$ & & \\
\hline
\end{tabular}

Table 2 Salient digital resources in phase 1

\subsection{Collaborating on standards (2012-2014)}

By 2012 STA were receiving multiple inquiries regarding when the promised services would be launched. This caused significant frustration within the marketing unit that was in charge of setting up new services since, from their perspective, this was an interesting technology but without any ready business cases or internal agents pushing service development. The marketing manager explains:

"The technician promised our customers more than we could deliver. We're a state agency and can't step into the market and promise many services. If we do so, then we may take market shares, and we are not allowed to do that."

As a result, the marketing and maintenance units set up an RFID group with the pronounced task of developing a web service based on this data for customers. Members included both people from the business side and technology-oriented staff.

As results started coming in from the pilot projects launched in the previous phase, the limitations of using OUT/IN as a gateway towards customers where increasingly acknowledged. In particular, the system did not support two-way communication to the extent needed for an efficient combination of data. To this end, other communication resources where explored. For STA, it was at this time considered important increasing the intermodal (multiple modes of transport such as road and railway traffic) capacity of the transport system, including the information infrastructure. The traffic planner explains:

"We should prepare our organization to work towards intermodality. In the future, we will be forced to exchange data with the other transport agencies."

The RFID group included multiple business developers with a background in road centered applications. These business developers pushed the intermodal aspect and argued that leveraging an existing system (Lastkajen) could be fruitful. Lastkajen mainly provided static data on roads and vehicles but was up and running and had proven functionality for external customers. Simultaneously, the technician engaged in projects to continue the work on technical evaluation of different RFID tags.

As the work on enabling information sharing across national train systems in Europe progressed, diversity in existing standards and technology was highlighted as a problem. Since the existing network of detectors varied between countries according to local or national demands concerning measurements and assessment methods, results were not comparable. The harmonization and data sharing efforts involved with the RFID technology thus sparked the HRMS project, and finally a standard solution to measuring, categorizing, and sharing detector data.

Meanwhile, the work in the 'RFID in rail' group went on, mainly focused on the exploration and development of the EPCIS standard. In three pilot projects, the standard was put into practical use together in conjunction with different types of RFID tags (passive and active). This resulted in the release of an updated version (1.1) of the standard in 2014. As a result, the RFID projects started to change character since STA increasingly engaged in larger EU projects, most notable projects that aimed to increased information sharing among different partners. A member from GS1 explains:

"The standard developed couldn't be in place without the great effort from both STA and FRA. They took the lead and prepared ...."

Through the new standard, information on the wagon number, time, location of the reading point, and direction of the train could be provided by the RFID tag. These new functionalities accentuated the need for two-way communication with the national vehicle register held by another state administration (Swedish Transport administration). Up until now this agency had not been very interested or accommodating, but the new standard and a simultaneous larger change of their internal IT systems led them to rethink and incorporate the needed functionality into their systems. The IT strategist at the Swedish transport agency explains:

"STA contacted us when we were updating our systems which were their salvation, otherwise we wouldn't be able to deliver the solution that fast"

Regarding focus, efforts increasingly focused on value creation in use of the technology. For example, projects gradually involved more personnel from operationally oriented units in exploring options for service development, and collaborations with researchers on service development commenced.

By the end of 2014, the test with Lastkajen as the gateway for providing web services had demonstrated that this was not a viable option since it was built for static data. In many ways, Lastkajen had the same limitations as OUT/IN. This became a wakeup call for proponents of maintaining and developing the existing structure formed around distinct systems with specific functionality. Instead, both service and system developers highlighted the 
need to rethink since the current resources hindered service development. To this end, the RFID group made the decision that a new structure was needed. A system developer explains:

"We are having the same problem with Lastkajen as with OUT/IN, while we were aiming for something more open and adjustable we are now working as statically as we did during our time using OUT/IN."

\begin{tabular}{|c|c|c|c|}
\hline Device & Network & Service & Content \\
\hline Detector, & Standardized & Customized & Data from \\
33 RFID & protocols, HMRS & prototypes & detector, \\
reading & and EPCIS. & for each & RFID, and \\
stations, & Customized & customer & OPERA \\
450 & prototypes for & through & \\
tagged & each customer & Lastkajen & \\
wagons & through & & \\
& Lastkajen & & \\
\hline
\end{tabular}

Table 3 Salient digital resources in phase 2

\subsection{Platform realization (2015-2017)}

The realization that the current systems did not provide the necessary functionality for combining a wide range of resources and enable service generation, lead STA to explore alternatives. In this process, it became increasingly clear for actors within STA that they should deter from developing predefined services. Instead, as a result of the number of specific requests, the increasing complexity, and organization of the IT industry, and governance regulations specifying their role in the market, STA's role was to provide the physical and digital infrastructure. As described by an IT strategist:

" We must provide raw data. We also need to understand our processes. But we should not develop services for the market, except those that belong to our core processes. We are responsible for providing services regarding our facilities, support for the processes we are involved in, and raw data. But developing apps regarding timetables or disturbances in the traffic, there are so many other actors than us that are better in doing that."

To this end, the RFID group decided to go for an internally developed solution that could leverage the different resources explored and generated in the previous phases. The idea was to create a platform capable of integrating data from these sources, provide confined raw data delivery according to access rights, and enable API's for both current and future requirements. In addition, the platform needed to be flexible enough to support future additions of data producing resources.

The outcome of the development process was a platform that integrated the existing resources for data generation. To distribute this data, an internal presentation solution for traffic management was developed and outbound connections to train drivers and customers (both for operational data and historical data on train elements that could be used by customers for data analysis). The platform integrated data from the national vehicle register, which based on the previous standardization and integration efforts communicated with the European Railroad Vehicle Register, and through EPCIS standards RFID readers along the rail. Also, it gathered data from OPERA on train configurations that was also combined with the RFID data. This data was combined with detector data (DPC3) to allow matching of deviation signals with specific wagons and wheel axes.

In this process, an essential cognitive shift occurred. Instead of the previous focus on specific systems with a responsible system owner that decided from the viewpoint of the specific system, actors started talking about IT infrastructures for combining resources:

" Names on systems, that's a bit outdated. When you use an application, for example, Word, that's a system. This is IT that reshapes something, it bakes, it kneads data, if that is done in one system or many, that is indifferent. We use information from multiple sources. This is not connections between systems, it is an infrastructure that we are building." Unit manager IT

At the beginning of 2017, the platform went live, and the services towards customers were introduced. While this marked the outcome of an emergent digital innovation process in which institutional work both shifted in aims and target, it was also the release of a foundation for future innovation processes. For example, based on the platform STA is exploring opportunities to increase information sharing with Danish authorities, a development likely to trigger further innovation of processes and digital resources.

\begin{tabular}{|c|c|c|c|}
\hline Device & Network & Service & Content \\
\hline Detectors, & GSM-R & Resources for & Data \\
245 RFID & (communicating & external actors & from \\
reading & GPS data, TLS & to & detectors, \\
stations, & (traffic & communicate & RFID, \\
4450 & management & and retrieve & OPERA, \\
tagged & system), & data. & and \\
wagons & HMRS, EPCIS. & Standardized & Swedish \\
& Linkages to & service for & Transport \\
& ERADIS (new & both external & agency \\
& shared & and internal & \\
& European & actors & \\
& database). & according to & \\
& & access rights. & \\
\hline
\end{tabular}

Table 4 Salient digital resources in phase 4 


\section{Discussion and implications}

Leveraging digital platforms to distribute tasks can have significant impact on the providing organization [17]. While extant research provides deep insights into the governance and dynamics of existing digital platform, the processes through which they emerge are less understood. Digital resources exhibit an extraordinary capacity for combinatorial innovation both regarding upfront design processes, and later use contexts [5]. These characteristics enable designers to draw on existing elements as building blocks, users to recombine resources in actions, and gradual adaptation of resources and their connections of technology in use as learnings are generated. However, digital innovation processes take place in institutional contexts where actors are cognitively limited and face opposition to change from established institutional arrangements.

Furthermore, outcomes of digital innovation processes by definition carries novelty and thus challenges the institution to varying degrees. Accordingly, innovation processes underlying digital platform emergence both involve institutional work to affect the context of such work, exploration of digital resources, and their potential for recombination. Our analysis contributes to the digital platform literature by (1) demonstrating the role of digital malleability in bypassing institutional resistance, (2) identifying temporal patterns and dependencies of activities, and (3) detecting distinct emphasis in types of institutional work.

In terms of the digital resources and their combinations, there was a progressive pattern of growth in the innovation process at STA. In the first phase, resources in the device and network layers $[3 ; 5]$ in particular needed to be identified, generated, implemented and combined to enable the later growth of content and services. As the available resources and understandings of their potential and limitations grew, the second phase moved from a focus on innovation of specific resources towards consideration of the architectural rules enabling combinations, including homogenization of data and standardization of couplings. The work practices in the first two phases did not only generate insights on the available resources, but it also came to affect cognitive structures regarding IT. Specifically, the technical experimentation lead to an increased understanding of the nature of digital innovation including blurred boundaries between innovation process and outcome, and the temporary and fluid nature of couplings between resources [2;7].

Regarding types and categories of institutional work, our analysis identifies distinct patterns across the phases of the innovation process. In the first phase, salient institutional work was mainly aimed at creating new digital resources and knowledge. As actors working to maintain the current configurations and beliefs where robust and held essential management positions, work to create new arrangements often revolved around avoiding resistance (e.g., mimicking and exploiting existing types of technology). Since the innovation process was characterized by discovery rather than development through packaging resources and implementing them in business processes, work to maintain was mostly passive in the sense that it involved responding to specific creation activities. The most significant change of institutional rules was updating standards. This was largely external practice work [22] as the standard instead was established at the EU level. Overall, activities in this phase where primarily aimed at exploring and customizing resources, and ways were found to avoid significant clashes involved with disrupting institutional arrangements. Instead, actors were able to create new ones within what was perceived as the existing order. However, the technician did engage in some disruptive practices such as demonstrating potential value for customers and promising future delivery of RFID based services that were not sanctioned by STA decision makers.

The second phase was characterized by institutional work on creating and developing standards. In contrast to phase 1 that focused on exploration of technical components and connectivity between a limited number of components, architectural aspects for interorganizational connectivity were essential in this phase. Work on standardization and boundary resources by necessity came to include issues such as interoperability, nomenclature, and harmonization. The work aimed at creation came to involve acts of disruption when the mechanisms underpinning the status quo of the IT infrastructure where obviously deficient. As the disruptive work involving customers in the previous phase came to affect STA, the mismatch between customers' expectation and the IT infrastructure became obvious. Initially, actors sought to accommodate these expectations by working to adapt and maintain the IT structures and established processes. However, by the end of this phase, it became apparent that this was not viable.

The efforts in the previous phases had convinced many of the most influential actors of the necessity to create new institutional arrangements and had disrupted cognitive structures. Thus, the third phase was mainly characterized by work to create the new institutional materialization. While for example work 
aimed at maintaining occurred, it was primarily directed at micro-level arrangements (as contrasted to opposing architectural changes). Across the phases, the malleability of digital technology allowed actors to draw on practices such as mimicking existing and accepted technology, thus circumventing some of the anticipated opposition.

\section{References}

[1] de Reuver, M., Sørensen, C., and Basole, R.C.: 'The digital platform: a research agenda', Journal of Information Technology, 2017, pp. 1-12

[2] Yoo, Y., Boland, R.J., Lyytinen, K., and Majchrzak, A.: 'Organizing for Innovation in the Digitized World', Organization Science, 2012, 23, (5), pp. 1398-1408

[3] Yoo, Y., Henfridsson, O., and Lyytinen, K.: 'Research commentary: The new organizing logic of digital innovation: an agenda for information systems research', Information Systems Research, 2010, 21, (4), pp. 724-735

[4] Tilson, D., Lyytinen, K., and Sorensen, C.: 'Research Commentary-Digital Infrastructures: The Missing IS Research Agenda', Information Systems Research, 2010, 21, (4), pp. 748-759

[5] Henfridsson, O., Nandhakumar, J., Scarbrough, H., and Panourgias, N.: 'Recombination in the open-ended value landscape of digital innovation', Information and Organization, 2018, 28, (2), pp. 89-100

[6] Eaton, B., Elaluf-Calderwood, S., Sørensen, C., and Yoo, Y.: 'Distributed Tuning of Boundary Resources: The Case of Apple s iOS Service System', MIS Quarterly, 2015, 39, (1), pp. 217-244

[7] Nambisan, S., Lyytinen, K., Majchrzak, A., and Song, M.: 'Digital Innovation Management: Reinventing Innovation Management Research in a Digital World', MIS Quarterly, 2017, 41, (1), pp. 223-238

[8] Hinings, B., Gegenhuber, T., and Greenwood, R.: 'Digital innovation and transformation: An institutional perspective', Information and Organization, 2018, 28, (1), pp. 52-61

[9] Gawer, A.: 'Bridging differing perspectives on technological platforms: Toward an integrative framework', Research Policy, 2014, 43, (7), pp. 1239-1249

[10] Tiwana, A., Konsynski, B., and Bush, A.: 'Platform Evolution: Coevolution of Platform Architecture, Governance and Environmental Dynamics', Information Systems Research, 2010, 21, (4), pp. 675-687

[11] Thomas, L.D., Autio, E., and Gann, D.M.: 'Architectural leverage: putting platforms in context', The Academy of Management Perspectives, 2014, 28, (2), pp. 198-219

[12] Skog, D., Wimelius, H., and Sandberg, J.: 'Digital Service Platform Evolution: How Spotify Leveraged Boundary Resources to Become a Global Leader in Music Streaming', HICSS 2018, pp. 4564-4573

[13] Svahn, F., Mathiassen, L., and Lindgren, R.: 'Embracing Digital Innovation in Incumbent Firms: How Volvo Cars Managed Competing Concerns', MIS Quarterly, 2017, 41, (1), pp. 239-254
[14] Sandberg, J., Holmström, J., and Lyytinen, K.: 'Platform Change: Theorizing the Evolution of Hybrid Product Platforms in Process Automation'. Proc. Platform Strategy Research Symposium, Boston MA2013

[15] Gawer, A.: 'Platforms, markets and innovation' (Edward Elgar Publishing, 2009. 2009)

[16] Evans, D.: 'How catalysts ignite: The economics of platform-based start-ups', Cheltenham, UK and Northampton, MA, US: Edward Elgar, 2009

[17] Parker, G., Van Alstyne, M., and Jiang, X.: 'Platform Ecosystems: How Developers Invert the Firm', MIS Quarterly, 2017, 41, (1), pp. 255-A254

[18] Huber, T.L., Kude, T., and Dibbern, J.: 'Governance Practices in Platform Ecosystems: Navigating Tensions Between Cocreated Value and Governance Costs', Information Systems Research, 2017, 28, (3), pp. 563-584

[19] Constantinides, P., Henfridsson, O., and Parker, G.G.: 'Introduction-Platforms and Infrastructures in the Digital Age', Information Systems Research, 2018, 29, (2), pp. 381-400

[20] Fichman, R.G., Dos Santos, B.L., and Zheng, Z.: 'Digital Innovation as a Fundamental and Powerful Concept in the Information Systems Curriculum', MIS Quarterly, 2014, 38, (2), pp. 329-A315

[21] Lawrence, T.B., and Suddaby, R.: 'Institutions and Institutional Work. Handbook of Organization Studies. SR Clegg, C. Hardy, TB Lawrence and W. Nord: 'Book Institutions and Institutional Work. Handbook of Organization Studies. SR Clegg, C. Hardy, TB Lawrence and W. Nord' (London, Sage, 2006, edn.).

[22] Gawer, A., and Phillips, N.: 'Institutional Work as Logics Shift: The Case of Intel's Transformation to Platform Leader', Organization Studies, 2013, 34, (8), pp. 1035-1071

[23] Scott, W.R.: 'Instituitions and organizations', Thousande Oakes: Sage, 2001

[24] Orlikowski, W.J., and Scott, S.V.: 'Sociomateriality: Challenging the Separation of Technology, Work and Organization', The academy of management annals, 2008, 2, (1), pp. 433-474

[25] Klein, H., and Myers, M.: 'A Set of Principles for Conducting and Evaluating Interpretive Field Studies in Information Systems', MIS Quarterly, 1999, 23, (1), pp. 67-94

[26] Walsham, G.: 'Interpretive Case Study in IS Research: Nature and Method', in Editor (Ed.) $)^{\wedge}$ Eds.): 'Book Interpretive Case Study in IS Research: Nature and Method' (1995, edn.), pp. 74-81

[27] Walsham, G.: 'Doing interpretive research', European journal of information systems, 2006, 15, (3), pp. 320-330

[28] Biernacki, P., and Waldorf, D.: 'Snowball sampling: Problems and techniques of chain referral sampling', Sociological methods \& research, 1981, 10, (2), pp. 141163

[29] Miles, M.B., and Huberman, A.M.: 'Qualitative Data Analysis: an expanded sourcebook' (Sage Publications, 1994. 1994)

[30] Charmaz, K.: 'Constructing Grounded Theory: A Practical Guide Through Qualitative Analysis' (Sage, 2006. 2006) 